\title{
Benefits and limitations of three-dimensional printing technology for ecological research
}

\author{
Jocelyn E. Behm ${ }^{1,2^{*}}$, Brenna R. Waite ${ }^{1,3}$, S. Tonia Hsieh ${ }^{4}$ and Matthew R. Helmus ${ }^{1}$
}

\begin{abstract}
Background: Ecological research often involves sampling and manipulating non-model organisms that reside in heterogeneous environments. As such, ecologists often adapt techniques and ideas from industry and other scientific fields to design and build equipment, tools, and experimental contraptions custom-made for the ecological systems under study. Three-dimensional (3D) printing provides a way to rapidly produce identical and novel objects that could be used in ecological studies, yet ecologists have been slow to adopt this new technology. Here, we provide ecologists with an introduction to 3D printing.

Results: First, we give an overview of the ecological research areas in which 3D printing is predicted to be the most impactful and review current studies that have already used 3D printed objects. We then outline a methodological workflow for integrating 3D printing into an ecological research program and give a detailed example of a successful implementation of our 3D printing workflow for 3D printed models of the brown anole, Anolis sagrei, for a field predation study. After testing two print media in the field, we show that the models printed from the less expensive and more sustainable material (blend of $70 \%$ plastic and $30 \%$ recycled wood fiber) were just as durable and had equal predator attack rates as the more expensive material (100\% virgin plastic).

Conclusions: Overall, 3D printing can provide time and cost savings to ecologists, and with recent advances in less toxic, biodegradable, and recyclable print materials, ecologists can choose to minimize social and environmental impacts associated with 3D printing. The main hurdles for implementing 3D printing - availability of resources like printers, scanners, and software, as well as reaching proficiency in using 3D image software - may be easier to overcome at institutions with digital imaging centers run by knowledgeable staff. As with any new technology, the benefits of 3D printing are specific to a particular project, and ecologists must consider the investments of developing usable 3D materials for research versus other methods of generating those materials.
\end{abstract}

Keywords: 3D models, Additive manufacturing, Anolis sagrei, Clay model, Curaçao, Maya autodesk, Sustainability

\section{Background}

Ecologists exhibit exceptional creativity and ingenuity in designing new tools and equipment for their studies, often incorporating and repurposing technology from other fields. For example, unique solutions have been devised for tracking animals (backpack-mounted radio transmitters [1]), tracking seeds (fluorescent pigments

\footnotetext{
*Correspondence: jebehm@temple.edu

${ }^{1}$ Integrative Ecology Lab, Center for Biodiversity, Department of Biology, Temple University, Philadelphia, PA, USA

Full list of author information is available at the end of the article
}

[2]; seed tags [3]), catching animals (pit-less pitfall traps [4]), containing or restraining difficult-to-hold specimens (squeeze box for venomous snakes [5], ovagram for amphibian eggs [6]), and remotely collecting data or samples (frog logger [7]; hair trap [8]), among countless others. Because many ecological studies require customized equipment, ecologists are no strangers to building the contraptions necessary for conducting their research, and the weeks leading up to and during field seasons and lab experiments often involve multiple trips to hardware stores and craft shops. 
Despite the high level of creativity and adaptability exhibited by ecologists, there is one technology that ecologists have been slower to adopt relative to other fields: three-dimensional (3D) printing. Additive layer manufacturing, or $3 \mathrm{D}$ printing, is the layering of material by a computer-controlled machine tool to create an object from a digital file that defines its geometry [9]. Most objects are printed in plastic, but newer print materials such as metal, wood, or other composites are increasingly common in consumer applications. In the recent past (i.e., before 2010), 3D printing was cost-prohibitive and limited in availability, but it is now affordable and accessible to budget-conscious ecologists. Many research institutions have at least one 3D printing center and 3D printing services are available to all online. Other fields, such as the health sciences, have readily adopted 3D printing into their research (e.g., [10]), but it is as of yet an untapped technology that ecologists can exploit to their advantage [11].

Recent studies have highlighted the benefits of 3D printing in terms of cost and time efficiency [12, 13], yet ecologists wanting to implement 3D printing for the first time must still traverse a steep learning curve. Our goal here is to flatten the curve and provide ecologists with a general but sufficient background in 3D printing technology to know what considerations are important when approaching a $3 \mathrm{D}$ printing project. In this article, we provide an overview of how $3 \mathrm{D}$ printing has been adopted by fields related to ecology. We highlight areas of ecological research where we think $3 \mathrm{D}$ printing has the promise to be most effective and provide a methodological workflow for integrating 3D printing into ecological studies. We illustrate this workflow using an example from our own work, which includes the obstacles we encountered and the solutions we devised. Finally, we conclude with important environmental sustainability considerations.

\section{Overview of 3D printing in fields related to ecology}

Two disciplines that were early adopters of 3D printing technology and have strong connections to ecology are biomechanics and natural history curation. Below we provide examples of 3D printing implementations in these fields to provide ecologists with ideas of what is possible.

The aim of biomechanics is to understand the movement and structure of living organisms integrating across physics, engineering, physiology, and ecology. In biomechanics, 3D printing is used to test how the shapes of particular appendages or biological structures function in the physical environment without having to use live organisms. For example, 3D printed models of the sandburrowing sandfish lizard's (Scincus scincus) respiratory system made it possible to study why it does not inhale sand in ways that are impossible with a living lizard's respiratory system [14]. In studies of fluid dynamics, 3D printed models of swift (Apus apus) wings and bodies of echolocating bat species permitted tests in water and wind tunnels respectively to understand how morphology influences species' movements $[15,16]$. In other applications, biomechanical theory is tested by attaching 3D printed structures to robots. In a study of underwater burrowing mimetics in bivalves, Germann et al. [17] used mathematical models to design a bivalve shell which was $3 \mathrm{D}$ printed and incorporated into a burrowing robot. In other studies, evolutionary optimization models are used to design the shape of anatomical structures. Then, 3D prints of the modeled and naturally occurring structures are compared in performance tests to understand the evolutionary limitations species face in structural adaptation in examples such as station keeping in aquatic environments, morphological optimization of balance and efficiency in fish, and seahorse tail shape morphology [18-20]. For these studies, 3D models enabled scientific inquiry, as manipulating live animals would have been challenging or impossible.

In the field of natural history curation, 3D printing increases the speed at which discoveries are made, and the rate at which data and resources are shared across natural history collections [21]. In paleontology, the reconstruction of complete skeletons is often impaired by the recovery of incomplete remains at dig sites. Mitsopoulou et al. [22] used mathematical allometric scaling models to calculate the dimensions of bones missing from the remains of a dwarf elephant (Paleoloxodon tiliensis) recovered from Charkadio Cave on Tilos Island, Greece. From these analyses, a 3D model was printed to allow the complete skeleton to be assembled. In addition, 3D technology also facilitates the sharing of museum material without having to loan valuable specimens, making it possible to construct complete skeletons using partial skeletons from multiple separate collections [23]. In fact, museums have been quick to adopt 3D technology because it vastly improves the rate at which collections are shared. The exchange of 3D-printed specimens facilitates crowd sourcing for specimen identification; access to high-quality replicas of endangered, extinct, or otherwise valuable and/or fragile specimens; and printed specimens can even be used in a field setting for species identification [23, 24]. Museums are increasingly accepting deposits of 3D printed material for rare and/ or difficult to access specimens. Lak et al. [25] employed 3D technology to describe two new damselfly species that were preserved in amber. Because it is difficult to physically extract amber-encased specimens without damaging them, the team used phase contrast X-ray synchrotron microradiography to make $3 \mathrm{D}$ images of the 
specimens and deposited the 3D prints in several museums. Finally, 3D technology also accelerates the flow of information for education and outreach. For example, Bokor et al. [26], developed a classroom exercise where students print fossilized horse teeth and examine how the teeth changed over time with respect to changing climate.

\section{Integration of 3D printing in ecology}

While ecologists have used 3D printing in a variety of applications (Table 1), there are four areas where we view $3 \mathrm{D}$ printing to be the most impactful: behavioral ecology, thermal ecology, building customized equipment, and enhancing collaboration.

The main goal of behavioral ecology is to understand how ecological and evolutionary forces shape behavior. In addition to observational studies, behavioral ecology research can involve manipulations of environmental conditions to test hypotheses. For testing hypotheses in both lab and field conditions, 3D printing may be incredibly useful for making precise, repeatable models. Threedimensional printing has already been used to create precise models of bird eggs to test egg rejection behavior in the context of brood parasitism [27], zebrafish shoals to test the effect of body size on zebrafish shoaling preferences [28], artificial flower corollas to test the effect of floral traits on pollinator visitation [29-31], and female turtle decoys to test the effect of body size on mate choice [32] (Table 1). In these studies, 3D printing was chosen for its ability to create identical experimental stimuli because alternative methods, such as constructing models by hand, could introduce unintentional variation that makes it difficult to determine whether study subjects are responding to intentional or unintentional variation in experimental stimuli. In addition, 3D printing is often a faster method for creating models than making them by alternative methods [13]. There may be scenarios where $3 \mathrm{D}$ printing will not produce more biologically accurate models than other methods, but in many cases, 3D printing will increase the types of behavioral questions that can be asked [27]. For example, northern map turtles (Graptemys geographica) are sensitive to captivity, and using 3D printed decoys of females permitted field studies of male mating behavior whereas using live females for the same study would have been detrimental to their survival [32]. Within the field of behavioral ecology research, 3D printing can be used to test myriad behaviors including predation (see "Workflow application"), reproduction, foraging, social interactions, and defense in both aquatic and terrestrial habitats.

Thermal ecology is focused on understanding how organisms are influenced by the temperature profile of their environment. A major challenge of thermal ecology research is constructing models that accurately replicate the thermal properties of a study organism. Copper models are often used, however, recent work demonstrated that 3D printed plastic models were cheaper and faster to construct and exhibited no difference in thermal properties compared to standard copper models (Table 1) [13]. This, as well as the need for high numbers of identical models, suggests that 3D printed models may make thermal ecology research more accessible.

Perhaps 3D printing will be the most helpful to the widest number of ecologists because it provides a method for constructing customized equipment such as tools and experimental habitats or mesocosms. In the field of soil ecology, 3D printing has been used to print artificial soil structures which accurately replicate the macropore structure of soil (Table 1) [33, 34]. These artificial soils are ideal replicate experimental mesocosms for soil macro- and/or microorganisms. Structures designed for other studies could be repurposed by ecologists as experimental habitats such as artificial gravel beds originally designed for testing water flow patterns [35] and artificial oyster shell reefs used to test how habitat complexity influences predation rates [36].

Opportunities for printing tools are limited primarily by the ecologists' imagination and range from simple structures to complex moving machines [37]. On the low-complexity end of the spectrum, 3D printing has been used to sample two difficult-to-catch, invasive, tree-boring beetle species that cause significant damage. Three-dimensional printed emergence traps make it possible to effectively trap and census invasive ambrosia beetles (Euwallacea fornicates) as they emerge from trees [38], while 3D printed decoys placed on standard beetle traps enhanced capture rates of invasive emerald ash borer beetles (Agrilus planipennis) [12]. In a more complex application, whale researchers used 3D printing to build an unmanned surface vehicle named SnotBot which allows scientists to get close enough to whales to collect biological samples (Table 1) [39]. There are ample opportunities for ecologists to design tools to aid in data collection, sample processing, organism containment, and even organization of field or lab spaces.

From the examples provided above, designing custom materials certainly benefits scientists within the context of a particular study. However, the use of 3D technology also provides a mechanism for collaboration that extends beyond the limits of a single study. Ecological studies that are replicated across systems, geographic boundaries, latitudinal gradients, etc., are a powerful method for testing ecological theory [40]. The use of 3D technology facilitates these broad-scale studies through the sharing of identical tools, models, and/or equipment that can be used in multiple systems. For example, 3D printed 


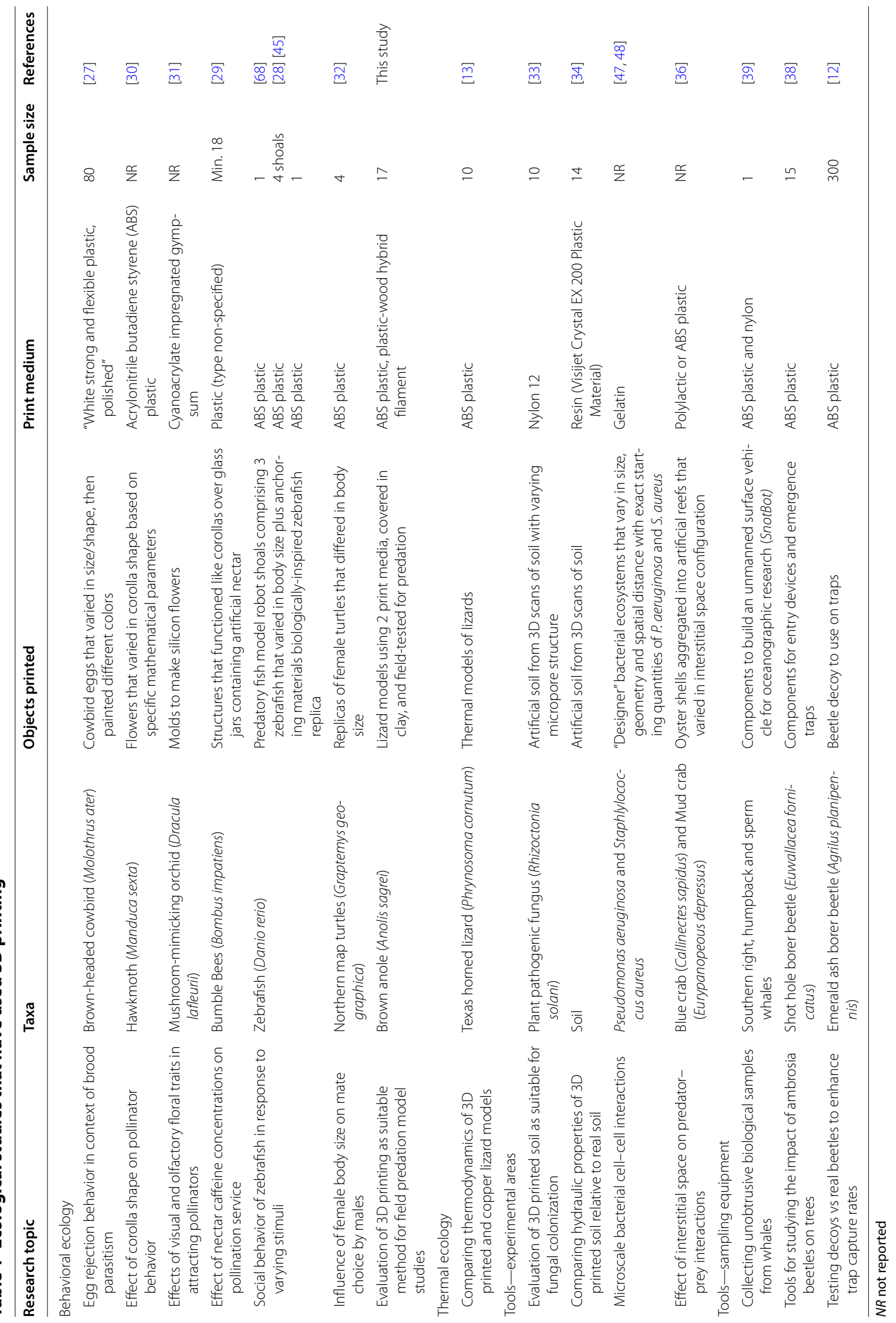


models of brown-headed cowbird (Molothrus ater) eggs [27] and Texas horned lizards (Phrynosoma cornutum) [13] can be used to test patterns of brood parasitism and thermal tolerances, respectively, across their geographic ranges. Similarly, for widespread invasive species like the emerald ash borer, sharing effective trap methodology [12] among scientists and agencies can potentially accelerate the rate at which the impact of the species is mitigated. In addition, 3D technology provides a useful platform for ecologists who would like to incorporate citizen scientists into a research program. Indeed, effective sampling technologies that can be disseminated electronically are ideal for citizen science, and increase the speed at which consistent data can be collected [41].

\section{Workflow methodology}

Below we describe a general workflow to use when embarking on incorporating 3D printing into ecological research. Essentially, once an ecologist has identified the object to be printed, the 3D printing process involves creating a printable 3D digital image file of the object, selecting an appropriate print media, and then printing draft and final versions of the object (Fig. 1). To be clear, details specific to each project and available resources will need to be explored and fine-tuned along the way. However, our workflow highlights the major steps and aspects to consider at the onset.

\section{Make a digital object file}

The first step is to generate a digital file of the object to be printed, which can be accomplished by creating a digital file of the image from scratch, converting a 2D image (e.g., photograph) into a 3D image, scanning an existing 3D object, or using an existing 3D file. All digital 3D files require use of software specifically for editing 3D images (Additional file 1). The most common 3D image file format is an STL file and is used by many software packages. Depending on the image generating methods used and the types of modifications needed, there may be a significant learning curve to attain the necessary level of proficiency on the software. This is especially true for creating a 3D image completely from scratch (see below). In our experience, however, we scanned an existing object and an undergraduate student was able to work together with the printing center staff to learn the software and manipulate the image within 2 months.

Before trying to create the image from scratch or scan an existing image, it may be worthwhile first to check the many libraries of 3D imagery that are available online (Additional file 2). It is possible that a digital 3D file of a similar object has already been created and can be downloaded potentially for free, ready to be printed. Even if the file in an online library is not exactly perfect, it can be

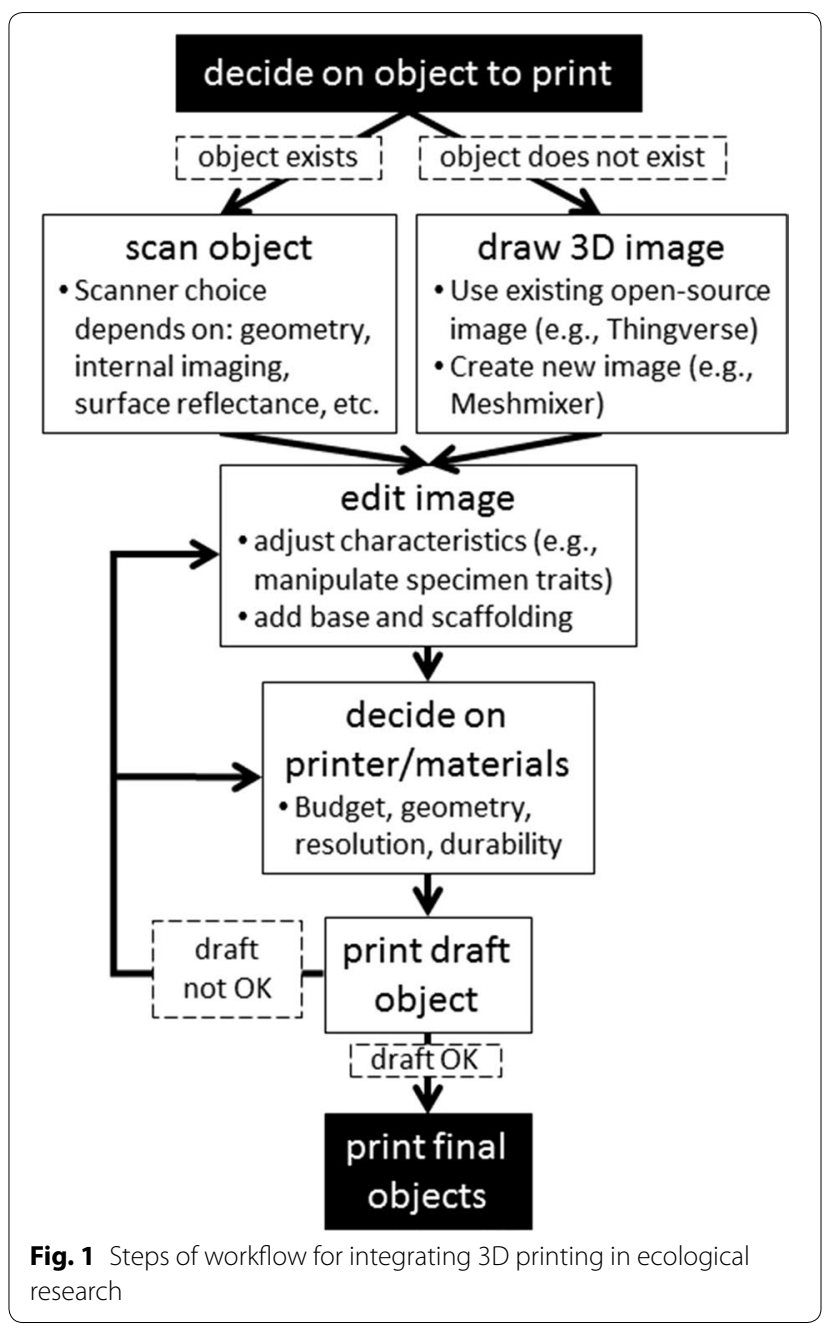

manipulated using 3D software (Additional file 1), which, depending on the modifications needed, may be a more efficient use of time than scanning an image or trying to draft an image from scratch.

If a suitable digital 3D file is not available, but the object to be printed is in the ecologist's possession, it is possible to use a 3D scanner to make a digital 3D image of the object, similar to how a flatbed scanner makes a digital 2D image of an object. There are various types of scanners, and it is necessary to choose a scanner that can accurately capture the level of detail needed for the project from the object being scanned. Laser scanners, structured light scanners, and even smart phone apps, can be used to create lower resolution scans of an object's external features. Laser scanners were used to scan Texas horned lizards that were frozen in realistic positions for a thermal ecology study (Makerbot Digitizer 3D, Makerbot, New York, USA) [13], and oyster shells for a biomechanical predation study (Vivid 9i, Konika Minolta Inc., Tokyo, Japan) [36]. For more complex and fine scale 
objects with both internal and external features like soil micropore structure or seahorse tail skeletal structure, methods like X-ray microtomography (HMX 225, Nikon Corp., Tokyo, Japan) [33] or micro-computed tomography scanning (Skyscan 1076, Kontich, Belgium) [20] may be more appropriate.

If the object to be printed is not in the ecologist's possession, it is possible to design the object using 3D drafting software (Additional file 1), with the time investment being proportional to the researcher's proficiency on the software and the complexity of the object. Using photogrammetry, photos can be digitized and $2 \mathrm{D} x, y$ coordinates from the photo converted into a 3D image [27, 42]. Photogrammetry may be the easiest and most cost effective method, especially if a scanner is not available. In addition, photogrammetry can be used to augment an image produced by 3D scanning: in the creation of 3D printed northern map turtle decoys, the carapace and legs of a dried specimen were scanned and the head was digitally rendered using photographs [32]. Alternatively, mathematical formulae may be used to generate different shapes, such as the surface of a bird egg [27] or the curvature of a flower corolla [30]. Finally, it is possible to draft the object completely from scratch (e.g., [38]), although a higher proficiency on the appropriate drafting software is necessary (Additional file 2).

Once a digital 3D image file is in hand, it will likely need to be edited and customized for the particular study. For example, in the brood parasitism study, the 3D image of the bird egg was edited to make it hollow so that the printed versions could be filled with water so their weight and thermal properties more closely matched a real bird egg [27]. Similarly, in the thermal ecology study, the 3D image of the Texas horned lizard was edited to include a well in the underside that fit a small environmental sensor (iButton) for measuring temperature [13]. Object size can also be manipulated and various polygons added to include additional structures.

Depending on the type of printer and material used, the image may need to be edited to make printing possible and to efficiently use printing material. Non-manifold geometry errors (i.e., geometry that cannot exist in the real world) can be common in scans made on biological objects and must be corrected to avoid fatal printing errors. Most 3D file manipulation software allows for these corrections (Additional file 1). Because most printers print the object from the bottom up layer-by-layer, any appendages or protrusions that extend out much wider than the bottom layer may need added scaffolding to make the print possible. This scaffolding is removed after printing is completed with varying degrees of effort depending on the design and print material. In addition, if the object is not flat, it will likely need a flat base added to make it printable. If multiple copies of the object are to be printed, it may be possible to rotate or stack them so that several copies can be printed simultaneously. This method ensures efficient use of printing platform space and materials.

\section{Printer and printing material}

There is a wide range of $3 \mathrm{D}$ printers that use various printing technologies and materials, and a comprehensive review of all printer types is beyond the scope of this article. For a technical review of various 3D printing technologies, we refer the reader to $[43,44]$. Here, we focus on the printers and materials likely to be most useful to ecologists. Many factors must be weighed when choosing a printer and printing material for a project, such as cost, material durability, printed surface quality, timeframe for printing, and color. The most ubiquitous printers that are common on university campuses and also through commercial online printing services typically use either plastic-based filament or resin as the print material. Filament is hard plastic stored on spools that is melted and deposited as beads or streams during printing that quickly re-harden into layers to form the object. Resin is a polymer liquid that is layered and solidified with UV light. Both come in a range of colors; filament is often cheaper but leads to a lower resolution print with printed bands more prominent on the finished object, however if needed there may be applicable surface finishing methods for smoothing out these bands, like using acetone vapor. Filament may also be less durable for some applications and cracks can form between layers if the object is subjected to physical stress. Finished resin products are generally smoother, can be printed at higher resolution, are more durable, and have the surface quality of a store-bought plastic item.

Both filament and resin have been used for printing low and high resolution ecological models, respectively. For example, acrylonitrile butadiene styrene (ABS), a type of filament, was used for printing artificial flowers [30], artificial zebrafish [28, 45], and models of lizards [13], while resin was used for printing artificial soils with finescale pore structure in a hydrology study [34]. It is also worth considering the type of scaffolding involved with a specific printer/print material combination. For some printing set-ups, the scaffolding is the same material as the printed object, which means the scaffolding must be physically cut off, creating opportunities to damage the printed object. Other printers are capable of dual or multi-extrusion, meaning they can print using different materials simultaneously. In this case, the scaffold material differs from the print material and can be dissolved after printing in a chemical solvent solution. 
More high-tech printers capable of printing even finerscale and more-detailed objects use a powder based print material which is converted into a solid plastic with a laser. An advantage of this print material is that little scaffolding is needed and extra powder can quickly be removed by shaking or brushing. This media was used to print soil pore microstructure at the scale of micrometers [33]. These artificial soils were printed using Nylon 12, a material that can be autoclaved, which makes it possible to reuse the soils for multiple experiments [33]. Although most standard printing materials are various types of plastic, there are a handful of products that include other materials like wood, rubber, and metal. At least one biodegradable plastic filament also exists: a polylactic acid (PLA) made from corn starch $[37,46]$.

There are two exceptionally technical printing applications that are not yet readily available to ecologists but may provide exciting opportunities soon. In one application, designer bacterial ecosystems that varied in geometry and spatial structure were printed using a gelatin-based material in order to study cell-to-cell interactions ([47, 48]; Table 1$)$. In a second application, nanoscale $3 \mathrm{D}$ printing technology was used to print replicas of abdominal scales from rainbow peacock spiders (Maratus robinsoni and $M$. chrysomelas) and specialized hairs from blue tarantulas (Poecilotheria metallica and Lampropelma violaceopes) with comparable visual properties to the actual structures $[49,50]$. Although these technologies are still under development, they could provide novel methods for testing community ecology theory and visual signaling hypotheses, respectively.

\section{Printing}

Once the 3D image has been drafted and edited, and the printer and print materials have been selected, a test round of printing is necessary before moving to the final round. Printing a test object makes it possible to identify errors with the $3 \mathrm{D}$ image file, compare print materials and confirm the material choice, and gain an estimate of the amount of time required for printing en masse. After all aspects of the printing project have been approved, the final prints can proceed.

\section{Post-processing}

Following printing, various post-processing stages will likely need to occur, such as removing scaffolding, painting, adding clay, and/or assembling pieces. It is particularly important to consider the sensory modality of the organism(s) under study with respect to how they will perceive and interact with the $3 \mathrm{D}$ printed object. While these considerations are important for any study using artificial models generated by $3 \mathrm{D}$ printing or otherwise,
3D printed materials may differ from other commonly used materials in their hardness, roughness, visual, and odor-related properties. Through post-processing methods, ecologists can insure that the $3 \mathrm{D}$ printing material does not interfere with their study.

\section{Workflow application: 3D printed Anolis lizards}

Here we provide an example of a successful attempt to integrate 3D printing into an ecological project following the workflow outlined above. We include the obstacles encountered along the way as a useful case study for other ecologists. Note, we used equipment (scanners and printers) and expertise from two (out of the four) 3D printing centers at our institution. For ecologists with fewer onsite resources, online resources and resources at collaborating institutions may be useful.

Clay animal models have long been used in ecological field research to infer predation rates by free-ranging predators on prey. In this methodology, animal models are constructed from plasticine modeling clay and then placed in the field for a fixed time period. Because the clay does not harden, predation attempts leave marks in the clay, making it possible to score models for evidence of predation. Early work used this method to study how body coloration affected predation rates in snakes [51, 52]. Since then, clay models have been used in predation studies to represent a wide range of taxa including frogs [53], salamanders [54], lizards [55], and insect larvae [56].

In many of these studies, models are constructed by hand either completely or nearly completely from clay (e.g., [52, 54, 56, 57]). In other studies, silicon molds are made from preserved specimens, which are then used to make models either directly out of clay [58], or out of plaster which is then covered with clay [59]. These methods clearly produce models that elicit responses in predators, however, producing the models in this manner can be time consuming as studies may use upwards of 100 models. In addition, modifying the models in a precise manner to test the effects of prey traits on predation is difficult. The repeatability, speed, and precision of $3 \mathrm{D}$ printing make it highly applicable to field studies of predation using models. We first explored the ease of creating a 3D scan of a preserved lizard specimen, and then used software to modify its body size. We then tested the durability of two print materials and two model sizes in a field predation study.

\section{Making the lizard model}

We used two methods, a structured light scanner (David SLS-2 3D Scanner, HP Inc., Palo Alto, CA, USA) and a laser scanner (NextEngine2020, NextEngine, Inc., Santa Monica, CA, USA), to make 3D scans of a preserved male 


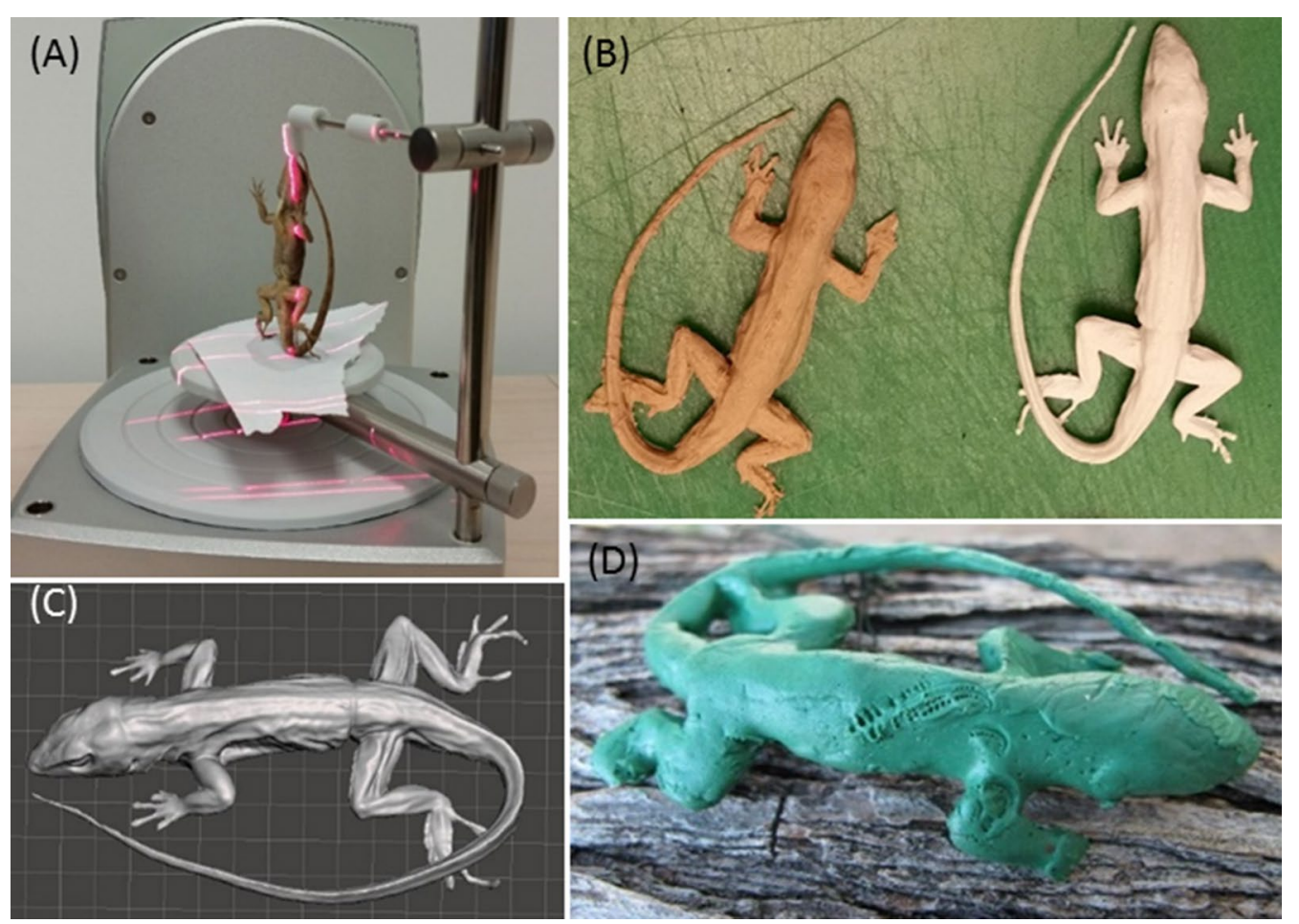

Fig. 2 Construction of a 3D printed lizard predation model A successful laser scanning setup of preserved brown anole (Anolis sagrei) specimen in vertical orientation; B 3D image of scanned anole viewed in Meshmixer software and later edited in Maya; C 3D printed plastic-wood hybrid (left) and ABS plastic (right) anole models; D clay covered model on a branch in the field with bite marks likely from a lizard predator (Cnemidophorus murinus murinus)

Anolis sagrei lizard. Structured light scanners operate by projecting light patterns onto the object being scanned and analyzing the pattern's deformation with a camera. The laser scanner we used boasts new technology consisting of more sophisticated algorithms and multiple lasers which scan in parallel, yielding more data points and an overall more accurate scan. Both scanners are designed to scan 3D objects, but because they use different technologies to do so, one scanner may be more effective for scanning a particular object. Regardless of the number of scans or angle of rotation, the structured light scanner's software was not able to converge the multiple scans into a single image of our anole, likely due to the complexity and high reflectance of the preserved specimen's skin. The laser scanner, however, was able to produce a digital 3D image of the specimen within about $90 \mathrm{~min}$, and we used this file going forward. The laser scanner was most successful when the lizard specimen was positioned in a vertical rather than flat manner using an Extra Part Gripper (NextEngine, Inc., Santa Monica, CA, USA; Fig. 2A).

We used Maya software (Autodesk, San Rafael, CA, USA; Additional file 2) to edit the scanned image (Fig. 2B) of the lizard specimen to attain three goals. First, to make the lizard scan possible to print, we had to edit the nonmanifold geometry errors that arose due to the scanning process. Second, we manipulated the size of the lizard to test whether different printing materials were durable for both large and small prints. The large lizard was $25 \%$ larger than the original (snout vent length $=60 \mathrm{~mm}$ ). Finally, we added a hollow horseshoe-shaped tube in the ventral side of the body cavity for looping a small wire through in order to anchor the models to branches in the field. The final file we used to print the lizards is included in Additional file 3.

\section{Print material and printing}

We tested two types of filament print media as bases for our clay models: plastic (ABS-P430 plastic in ivory, Stratasys, Eden Prairie, MN, USA) and plastic-wood hybrid (Woodfill by ColorFabb, Belfeld, the Netherlands). ABS exceeded the Woodfill in cost and perceived durability, yet Woodfill was a more sustainable option as it is made of $30 \%$ recycled wood fibers. During our test print stage, we learned we needed to add a base to our digital 3D image file for the Woodfill prints because the scanned image was not flat which made it 
difficult to print. We did not need to edit it for the ABS print because the scaffold base dissolved.

After we finalized our 3D image files from the test print stage, we printed 10 ABS models on a Dimension Elite Printer (Stratasys, Eden Prairie, MN, USA) and seven plastic-wood hybrid models on a BigBox 3D Printer (Chalgrove, UK) (Fig. 2C). We had intended to print equal numbers of each, however, the printer using the Woodfill kept getting jammed and starting over, and seven was all we could print in the timeframe we had available. The printer jamming was due in part to the print material and due to errors in the file geometry that were not adequately resolved during the editing stage. In total, it took about $8 \mathrm{~h}$ to print the $10 \mathrm{ABS}$ lizards plus an additional $4 \mathrm{~h}$ to dissolve the scaffolding. It took nearly 5 days to print the seven plasticwood hybrid models (due to the printer jamming), and the scaffolding needed to be cut off by hand using an Exacto knife which took about an hour for all seven models. If the printer had not jammed, it would have taken $2 \mathrm{~h}$ per model to print.

It was quite difficult to thread the narrow floral wire (26 gage, Panacea Products, Columbus, OH, USA) through the ventral holes in both Woodfill and ABS of models. The tube we made was curved, and in hindsight it should have been straight through the lizard midsection. Instead, we wrapped the wire around the midsection of the bodies with two long ends hanging off the ventral side. We then dipped all ABS and Woodfill models in melted plasticine clay (Craft Smart, Irving, TX, USA) to completely cover all parts of the body and the wire wrapped around the midsection. After the clay solidified (about $30 \mathrm{~min}$ ), we folded the wire and wrapped each lizard in aluminum foil for transport to the field.

In total, our time investment from scanning to printing was relatively low: it took $20 \mathrm{~h}$ from scanning the specimen to our first test print. Additional manipulations to the image took an additional $40 \mathrm{~h}$ (an undergraduate working $5 \mathrm{~h}$ /week for 2 months). Although we had to troubleshoot issues with our image and printing, the process was relatively easy due to the resources available at the 3D print centers (namely staff to mentor undergraduate on image software and troubleshoot printing issues), and that we did not need the surface to be an exact biological replica because we covered all models with clay.

\section{Field testing lizard models}

To test the effectiveness of both printing materials as bases for clay-covered models in the field, all clay-covered ABS and Woodfill lizard models were deployed in natural and developed habitats on the island of Curaçao (Dutch Antilles) for 24-48 $\mathrm{h}$ and then scored for predation. In both habitat types, models were anchored to tree branches, bushes, or rocks on the ground using the floral wire. We recorded evidence of predation from likely lizard and avian predators based on marks left in the soft clay (Fig. 2D). We considered two components of effectiveness: (1) do predators perceive and interact with the two print materials in the same manner (indicated by equal predation rates); (2) are both print materials durable to field conditions? While there was much higher predation in natural compared to developed sites $\left(\mathrm{F}_{1,30}=17.15, P<0.001\right)$, predators exhibited equal attack rates on $\mathrm{ABS}$ and Woodfill models $\left(\mathrm{F}_{1,30}=0.48, P=0.49\right)$

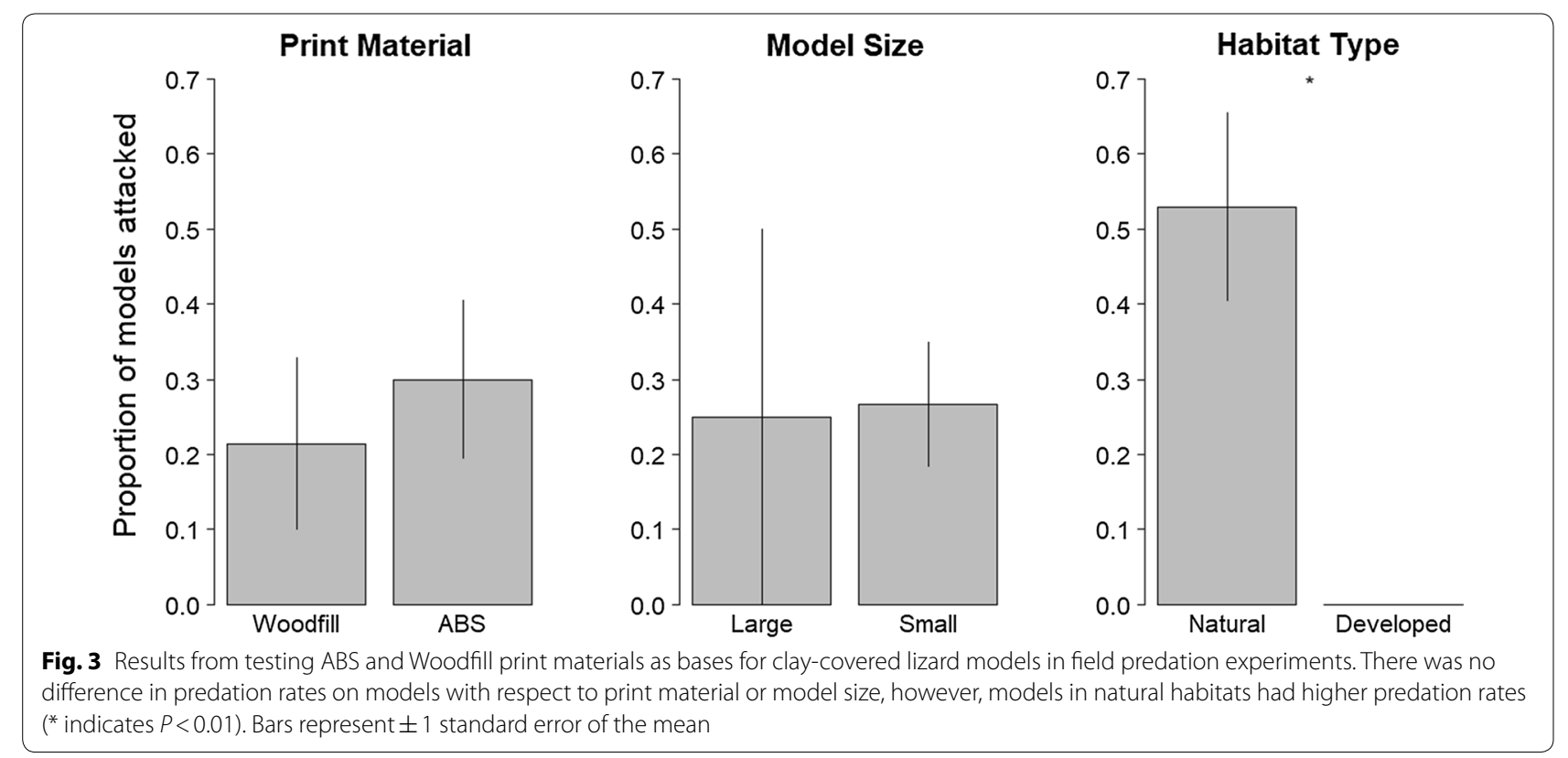


as well as on small and large models $\left(F_{1,30}=0.01\right.$, $P=0.93$ ) (Fig. 3). Both 3D print material types were durable to the field conditions and none of our models experienced any structural problems during the experiment. We concluded that both ABS and Woodfill were effective print materials to use as bases for clay-covered lizard models in field predation studies.

\section{Discussion}

\section{Recommendations for using 3D printed models for field predation studies}

Because the Woodfill models were cheaper and just as durable as the less sustainable ABS models, we would recommend using the Woodfill, or other similar plastics in comparable future studies, provided that the jamming issues we encountered during printing can be attributed to geometry errors in our file and not the Woodfill material itself. It should be noted that although we tested the models in extremely hot $\left(>35{ }^{\circ} \mathrm{C}\right)$ field conditions, we cannot comment on the durability of the two materials in rainy or very cold conditions. Initially, we believed the Woodfill would crumble more on the smaller model with narrower appendages, but this was not the case. Finally, our study took place over a 3-week period. It is possible that over longer time periods, the Woodfill would not be as durable as the ABS plastic.

\section{Reduce, reuse, recycle}

While 3D printing can facilitate ecological research, the use of this technology must be weighed against its environmental and social costs. In general, 3D printing can to reduce $\mathrm{CO}_{2}$ emissions and lead to more sustainable practices in the consumer manufacturing industry [60], yet there are many less sustainable aspects to consider. Three-dimensional printing is energy intensive and often uses fossil fuel derived virgin plastics which can exist in the environment for ages after disposal and can be toxic to aquatic organisms, especially resin-based printed objects [61]. The printing process itself generates waste due to printers jamming, misprinted models, and scaffolding necessary for more complex 3D objects, as well as harmful emissions in the form of ultra-fine particles and volatile organic compounds [62,63], which is especially worrisome as most 3D printers are housed in indoor office settings [64]. With respect to the manufacturing of any plastic item, these negative aspects are not completely unique to $3 \mathrm{D}$ printing, they just become more obvious when one is directly involved in the manufacturing process. In our specific case, we chose 3D printed models for the speed at which they could be produced and their durability as we intend to use them in future experiments. Ecologists planning to incorporate 3D printing in research should strongly consider the negative impacts associated with 3D printing compared to the impacts of creating objects via other methods or not at all.

There are promising advances in the sustainability of 3D printing materials. Materials scientists are developing a range of filaments that are biodegradable, compostable, and made from recycled materials. For example, Eco-Filaments, such as WillowFlex (BioInspiration, Eberswalde, Germany), are made from plant-based resources and are completely compostable, even in residential compost bins. Other filament choices are made from recycled plastics like car dashboards, PET bottles, and potato chip bags (3D Brooklyn, Brooklyn, NY, USA; Refil, Rotterdam, the Netherlands). In fact, the cost of generating recycled plastic filament is often less than making filament from raw materials, prompting the establishment of a fair trade market for used plastic collected by waste pickers in the developing world (e.g., Protoprint Solutions, Prune, India) [65]. Non-plastic recycled filament options exists, such as filament made from the waste products of beer, coffee, and hemp production processes (3DFUEL, Fargo, ND, USA) as well as wood pulp [66]. Finally, because common print materials such as ABS plastic are not biodegradable or recyclable in municipal recycling centers, machines have been developed to recycle these plastics directly at the printing site [67]. These machines grind old prints and melt them into new filament that can be reused for printing (e.g., Filastruder, Snellville, GA, USA). Across sustainable options for print materials, we can attest to the durability of Woodfill for applications comparable to ours. For ecologists considering other sustainable print materials, most of these companies readily provide information about the durability of their products.

We stress that all 3D printing projects in ecological research should reduce, reuse, and recycle: Reduce the amount printed and the use of toxic print materials; Reuse printed objects and use materials made from postconsumer, waste materials; and Recycle printed objects by choosing materials that can be easily recycled, composted, or that are biodegradable. Planning a print job (Fig. 1) requires both careful estimation of the minimum number of replicates to print and smart design of geometry that minimizes or eliminates scaffolding, as scaffolding is usually discarded. Printing should be performed in well-ventilated environments where airborne toxins do not accumulate and harm personnel. The environmental toxicity of objects should be reduced by choosing materials with low toxic potential and reducing the toxicity of materials post-print. For example, exposure of resinbased printed objects to intense UV light can reduce their toxicity to aquatic organisms [61]. Printed objects should be reused in research as much as possible to avoid 
repeat printing, and print materials made from recycled material or materials that are recyclable or compostable should be used when possible. While most ecologists will not invest in their own 3D printing equipment and instead employ general-use academic (e.g., library) or commercial facilities, these environmental concerns can be communicated to the printing facilities so that they might adopt sustainable practices in their $3 \mathrm{D}$ printing for research.

\section{Conclusions}

In conclusion, 3D printing technology has the promise to reduce the time and cost invested in creating custom materials used in ecological research, while at the same time increasing the ease at which collaborations occur within and outside the scientific community. Although there is a learning curve for developing 3D image files, there are ample online libraries of 3D files, plus tech savvy students and 3D printing center staff can be extremely helpful. Recent advances in print materials may reduce the footprint associated with this new technology. Overall, as with any new technology, ecologists must weigh the costs in terms of time and monetary investments into developing usable 3D materials for research versus other methods of generating those materials. If ecologists are in the position to commit the initial investment in securing printing resources and navigating the technological learning curve, the resulting ability to implement 3D printing into future studies could save time and money on the long term.

\section{Additional files}

Additional file 1. Software for designing, modifying, and analyzing 3D files.

Additional file 2. Online libraries of 3D imagery relevant for ecological research (as of 2017).

Additional file 3. 3D image file (STL format) of Anolis sagrei lizard we made.

\section{Authors' contributions}

$\mathrm{JB}$ and $\mathrm{MH}$ conceived of and designed the study; JB, BW, and $\mathrm{MH}$ developed the workflow; BW tested the workflow and designed the 3D model; JB and $\mathrm{MH}$ conducted the field experiment; JB, BW, STH, and MH wrote the manuscript and provided editorial advice. All authors read and approved the final manuscript.

\section{Author details}

${ }^{1}$ Integrative Ecology Lab, Center for Biodiversity, Department of Biology, Temple University, Philadelphia, PA, USA. ${ }^{2}$ Department of Ecological Science-Animal Ecology, VU University Amsterdam, Amsterdam, The Netherlands. ${ }^{3}$ School of Biological Sciences, University of Western Australia, Perth, WA, Australia.

${ }^{4}$ Department of Biology, Temple University, Philadelphia, PA, USA.

\section{Acknowledgements}

We are grateful to two anonymous reviewers who provided useful comments that improved the quality of this manuscript. We thank J. Hample from the Digital Scholarship Center, S. Campbell from the Digital Fabrication Studio, and C. Denison from the Health Sciences Library Print Center all at Temple University for assistance with scanning and printing the lizard models. We thank M. Vermeij and S. Berendse from the Carmabi Foundation for logistical support in Curaçao. Finally, we thank S.B. Hedges for access to the preserved Anolis sagrei specimen.

\section{Competing interests}

The authors declare that they have no competing interests.

\section{Availability of data and materials}

The datasets used and/or analysed during the current study are available from the corresponding author on reasonable request.

\section{Consent for publication}

Not applicable.

\section{Ethics approval and consent to participate}

All work conducted involving live animals was in accordance with the Institutional Animal Care and Use Committee at Temple University (IACUC protocol \#4614).

\section{Funding}

This work was supported by funds from the Netherlands Organization for Scientific Research (858.14.040) and Temple University.

\section{Publisher's Note}

Springer Nature remains neutral with regard to jurisdictional claims in published maps and institutional affiliations.

Received: 14 December 2017 Accepted: 3 September 2018

Published online: 10 September 2018

\section{References}

1. Small RJ, Rusch DH. Backpacks vs. Ponchos: survival and movements of radio-marked ruffed grouse. Wildlife Soc Bull (1973-2006). 1985;13:163-5.

2. Reiter J, Curio E, Tacud B, Urbina H, Geronimo F. Tracking bat-dispersed seeds using fluorescent pigment. Biotropica. 2006;38:64-8.

3. Xiao Z, Jansen PA, Zhang Z. Using seed-tagging methods for assessing post-dispersal seed fate in rodent-dispersed trees. For Ecol Manage. 2006:223:18-23.

4. Patrick LB, Hansen A. Comparing ramp and pitfall traps for capturing wandering spiders. J Arachnol. 2013:41:404-6.

5. Quinn H, Jones JP. Squeeze box technique for measuring snakes. Herpetol Rev. 1974:5:35.

6. Karraker NE. A new method for estimating clutch sizes of ambystomatid salamanders and ranid frogs: introducing the ovagram. Herpetol Rev. 2007;38:46-8

7. Peterson CR, Dorcas ME. Automated data acquisition. In: Heyer RW, Donnelly MA, McDiarmid RW, Hayek LC, Foster MS, editors. Measuring and monitoring biological diversity: standard methods for amphibians. Washington, DC: Smithsonian Institution; 1994. p. 47-57.

8. Pauli JN, Hamilton MB, Crain EB, Buskirk SW. A single-sampling hair trap for mesocarnivores. J Wildlife Manag. 2008;72:1650-2.

9. Conner BP, Manogharan GP, Martof AN, Rodomsky LM, Rodomsky CM, Jordan DC, et al. Making sense of 3-D printing: creating a map of additive manufacturing products and services. Addit Manuf. 2014;1-4:64-76.

10. Mironov V, Kasyanov V, Drake C, Markwald RR. Organ printing: promises and challenges. Regen Med. 2008;3:93-103.

11. Allan BM, Nimmo DG, lerodiaconou D, VanDerWal J, Koh LP, Ritchie EG. Futurecasting ecological research: the rise of technoecology. Ecosphere. 2018;9:e02163.

12. Domingue MJ, Pulsifer DP, Lakhtakia A, Berkebile J, Steiner KC, Lelito JP, et al. Detecting emerald ash borers (Agrilus planipennis) using branch traps baited with 3D-printed beetle decoys. J Pest Sci. 2015;88:267-79. 
13. Watson CM, Francis GR. Three dimensional printing as an effective method of producing anatomically accurate models for studies in thermal ecology. J Therm Biol. 2015;51:42-6.

14. Stadler AT, Vihar B, Günther M, Huemer M, Riedl M, Shamiyeh S, et al. Adaptation to life in aeolian sand: how the sandfish lizard, Scincus scincus, prevents sand particles from entering its lungs. J Exp Biol. 2016;219:3597-604.

15. van Bokhorst $E$, de Kat R, Elsinga GE, Lentink D. Feather roughness reduces flow separation during low Reynolds number glides of swifts. J Exp Biol. 2015;218:3179-91.

16. Vanderelst D, Peremans $H$, Razak NA, Verstraelen E, Dimitriadis G. The aerodynamic cost of head morphology in bats: maybe not as bad as it seems. PLoS ONE. 2015;10:e0118545.

17. Germann DP, Schatz W, Hotz PE. Artificial Bivalves-the biomimetics of underwater burrowing. Procedia Comput Sci. 2011;7:169-72.

18. Moore JM, Clark AJ, McKinley PK. Evolution of station keeping as a response to flows in an aquatic robot. In: Proceedings of the 15th annual conference on Genetic and evolutionary computation. ACM 2013. p. 239-46. http://dl.acm.org/citation.cfm?id=2463402. Accessed 20 Nov 2016

19. Clark AJ, Wang J, Tan X, McKinley PK. Balancing performance and efficiency in a robotic fish with evolutionary multiobjective optimization In: 2014 IEEE International Conference on Evolvable Systems (ICES). 2014. p. 227-34.

20. Porter MM, Adriaens D, Hatton RL, Meyers MA, McKittrick J. Why the seahorse tail is square. Science. 2015;349:aaa6683.

21. Ziegler A, Menze B. Accelerated acquisition, visualization, and analysis of Zoo-Anatomical Data. In: Computation for humanity. Boca Raton: CRC Press; 2013. p. 235-64. http://www.crcnetbase.com/doi/ abs/10.1201/b15617-14. Accessed 20 Nov 2016.

22. Mitsopoulou V, Michailidis D, Theodorou E, Isidorou S, Roussiakis S, Vasilopoulos T, et al. Digitizing, modelling and 3D printing of skeletal digital models of Palaeoloxodon tiliensis (Tilos, Dodecanese, Greece). Quatern Int. 2015;379:4-13.

23. Niven L, Steele TE, Finke H, Gernat T, Hublin J-J. Virtual skeletons: using a structured light scanner to create a 3D faunal comparative collection. J Archaeol Sci. 2009;36:2018-23.

24. Raupach MJ, Amann R, Wheeler QD, Roos C. The application of "-omics" technologies for the classification and identification of animals. Org Divers Evol. 2016;16:1-12

25. Lak M, Fleck G, Azar D, Engel Fls MS, Kaddumi HF, Neraudeau D, et al. Phase contrast $X$-ray synchrotron microtomography and the oldest damselflies in amber (Odonata: Zygoptera: Hemiphlebiidae). Zool J Linn Soc. 2009;156:913-23.

26. Bokor J, Broo J, Mahoney J. Using fossil teeth to study the evolution of horses in response to a changing climate. Am Biol Teach. 2016;78:166-9

27. Igic B, Nunez V, Voss HU, Croston R, Aidala Z, López AV, et al. Using 3D printed eggs to examine the egg-rejection behaviour of wild birds. PeerJ. 2015;3:e965.

28. Bartolini T, Mwaffo V, Showler A, Macrì S, Butail S, Porfiri M. Zebrafish response to $3 \mathrm{D}$ printed shoals of conspecifics: the effect of body size. Bioinspir Biomim. 2016;11:026003.

29. Thomson JD, Draguleasa MA, Tan MG. Flowers with caffeinated nectar receive more pollination. Arthropod Plant Interact. 2015;9:1-7.

30. Campos EO, Bradshaw HD, Daniel TL. Shape matters: corolla curvature improves nectar discovery in the hawkmoth Manduca sexta. Funct Ecol. 2015:29:462-8.

31. Policha T, Davis A, Barnadas M, Dentinger BTM, Raguso RA, Roy BA. Disentangling visual and olfactory signals in mushroom-mimicking Dracula orchids using realistic three-dimensional printed flowers. New Phytol. 2016;210:1058-71.

32. Bulté G, Chlebak RJ, Dawson JW, Blouin-Demers G. Studying mate choice in the wild using 3D printed decoys and action cameras: a case of study of male choice in the northern map turtle. Anim Behav. 2018;138:141-3.

33. Otten W, Pajor R, Schmidt S, Baveye PC, Hague R, Falconer RE. Combining $\mathrm{X}$-ray $\mathrm{CT}$ and $3 \mathrm{D}$ printing technology to produce microcosms with replicable, complex pore geometries. Soil Biol Biochem. 2012:51:53-5.

34. Dal Ferro N, Morari F. From real soils to 3D-printed soils: reproduction of complex pore network at the real size in a silty-loam soil. Soil Sci Soc Am J. 2015:79:1008-17.
35. Bertin S, Friedrich H, Delmas P, Chan E. Gimel'farb G. Dem quality assessment with a 3D printed gravel bed applied to stereo photogrammetry. Photogram Rec. 2014;29:241-64.

36. Hesterberg S. Three-dimensional interstitial space mediates predator foraging success in different spatial arrangements. Masters Thesis. University of South Florida; 2016. http://scholarcommons.usf.edu/etd/6096. Accessed 20 Nov 2016.

37. Mohammed JS. Applications of 3D printing technologies in oceanography. Methods Oceanogr. 2016;17:97-117.

38. Berry D, Selby RD, Horvath JC, Cameron RH, Porqueras D, Stouthamer R. A modular system of 3D printed emergence traps for studying the biology of shot hole borers and other scolytinae. J Econ Entomol. 2016:109:969-72.

39. Bennett A, Barrett D, Preston V, Woo J, Chandra S, Diggins D, et al. Autonomous vehicles for remote sample collection enabling marine research. In: Proc. IEEE/MTS OCEANS. Genova; 2015. p. 8.

40. Borer ET, Harpole WS, Adler PB, Lind EM, Orrock JL, Seabloom EW, et al. Finding generality in ecology: a model for globally distributed experiments. Methods Ecol Evol. 2014;5:65-73.

41. Newman G, Wiggins A, Crall A, Graham E, Newman S, Crowston K. The future of citizen science: emerging technologies and shifting paradigms. Front Ecol Environ. 2012;10:298-304.

42. Rochman D, Luna ED. Prototyping the complex biological form of the beetle Deltochilum lobipes via 2D geometric morphometrics landmarks and descriptive geometry for 3D printing. Comput Aided Des Appl. 2017;14:107-16.

43. Garcia J, Yang Z, Mongrain R, Leask RL, Lachapelle K. 3D printing materials and their use in medical education: a review of current technology and trends for the future. BMJ Simul Technol Enhanc Learn. 2018;4:27-40.

44. Pucci JU, Christophe BR, Sisti JA, Connolly ES. Three-dimensional printing: technologies, applications, and limitations in neurosurgery. Biotechnol Adv. 2017;35:521-9.

45. Ruberto T, Polverino G, Porfiri M. How different is a 3D-printed replica from a conspecific in the eyes of a zebrafish?: how does a zebrafish see a replica? J Exp Anal Behav. 2017;107:279-93.

46. Tabone MD, Cregg JJ, Beckman EJ, Landis AE. Sustainability metrics: life cycle assessment and green design in polymers. Environ Sci Technol. 2010;44:8264-9.

47. Connell JL, Ritschdorff ET, Whiteley M, Shear JB. 3D printing of microscopic bacterial communities. PNAS. 2013;110:18380-5.

48. Connell JL, Kim J, Shear JB, Bard AJ, Whiteley M. Real-time monitoring of quorum sensing in 3D-printed bacterial aggregates using scanning electrochemical microscopy. PNAS. 2014;111:18255-60.

49. Hsiung B-K, Siddique RH, Stavenga DG, Otto JC, Allen MC, Liu Y, et al. Rainbow peacock spiders inspire miniature super-iridescent optics. Nat Commun. 2017;8:2278. https://doi.org/10.1038/s41467-017-02451-x.

50. Hsiung B-K, Siddique RH, Jiang L, Liu Y, Lu Y, Shawkey MD, et al. Tarantulainspired noniridescent photonics with long-range order. Adv Opt Mater. 2017:5:1600599.

51. Madsen T. Are juvenile grass snakes, Natrix-Natrix, aposematically colored. Oikos. 1987:48:265-7.

52. Brodie E. Differential avoidance of coral snake banded patterns by freeranging avian predators in Costa Rica. Evolution. 1993:47:227-35.

53. Flores EE, Stevens M, Moore AJ, Rowland HM, Blount JD. Body size but not warning signal luminance influences predation risk in recently metamorphosed poison frogs. Ecol Evol. 2015;5:4603-16.

54. Kraemer AC, Serb JM, Adams DC. Both novelty and conspicuousness influence selection by mammalian predators on the colour pattern of Plethodon cinereus (Urodela: Plethodontidae). Biol J Lin Soc. 2016:118:889-900.

55. Sato CF, Wood JT, Schroder M, Green K, Osborne WS, Michael DR, et al. An experiment to test key hypotheses of the drivers of reptile distribution in subalpine ski resorts. J Appl Ecol. 2014;51:13-22.

56. Peisley RK, Saunders ME, Luck GW. Cost-benefit trade-offs of bird activity in apple orchards. PeerJ. 2016;4:e2179.

57. Vazquez B, Hilje B. How habitat type, sex, and body region influence predatory attacks on Norops lizards in a pre-montane wet forest in Costa Rica: an approach using clay models. Herpetol Notes. 2015;8:205-12.

58. Yeager J, Wooten C, Summers K. A new technique for the production of large numbers of clay models for field studies of predation. Herpetol Rev. 2011:42:357-9. 
59. Gifford ME, Herrel A, Mahler DL. The evolution of locomotor morphology, performance, and anti-predator behaviour among populations of Leiocephalus lizards from the Dominican Republic. Biol J Lin Soc. 2008;93:445-56.

60. Gebler M, Schoot Uiterkamp AJM, Visser C. A global sustainability perspective on 3D printing technologies. Energy Policy. 2014;74:158-67.

61. Oskui SM, Diamante G, Liao C, Shi W, Gan J, Schlenk D, et al. Assessing and Reducing the Toxicity of 3D-Printed Parts. Environ Sci Technol Lett. 2016:3:1-6.

62. Azimi P, Zhao D, Pouzet C, Crain NE, Stephens B. Emissions of ultrafine particles and volatile organic compounds from commercially available desktop three-dimensional printers with multiple filaments. Environ Sci Technol. 2016;50:1260-8.

63. Yi J, LeBouf RF, Duling MG, Nurkiewicz T, Chen BT, Schwegler-Berry D, et al. Emission of particulate matter from a desktop three-dimensional (3D) printer. J Toxicol Environ Health Part A. 2016;79:453-65.
64. Steinle P. Characterization of emissions from a desktop 3D printer and indoor air measurements in office settings. J Occup Environ Hyg. 2016;13:121-32.

65. Feeley S, Wijnen B, Pearce JM. Evaluation of potential fair trade standards for an ethical 3-D printing filament. J Sustain Dev. 2014;7:1-12.

66. Gardan J, Roucoules L. 3D printing device for numerical control machine and wood deposition. Julien Gardan Int J Eng Res Appl. 2015;4:123-31.

67. Baechler C. Matthew DeVuono, Joshua M. Pearce. Distributed recycling of waste polymer into RepRap feedstock. Rapid Prototyp J. 2013;19:118-25.

68. Cianca V, Bartolini T, Porfiri M, Macrì S. A robotics-based behavioral paradigm to measure anxiety-related responses in zebrafish. PLoS ONE. 2013;8:e69661.
Ready to submit your research? Choose BMC and benefit from:

- fast, convenient online submission

- thorough peer review by experienced researchers in your field

- rapid publication on acceptance

- support for research data, including large and complex data types

- gold Open Access which fosters wider collaboration and increased citations

- maximum visibility for your research: over $100 \mathrm{M}$ website views per year

At BMC, research is always in progress.

Learn more biomedcentral.com/submissions 